\title{
CROSS-CULTURAL EDUCATION FOR INTERNATIONAL STUDENTS WHO INTERACT WITH JAPANESE PEOPLE: PRACTICAL LEARNING USING ROLE-PLAYS
}

\author{
Sachiko Nakano \\ International Students Center, Yamaguchi University (Japan)
}

\begin{abstract}
This research aims to propose a style of cross-cultural education that can teach students how to behave and converse in a practical way with Japanese people in social situations by using role-plays. Role-plays were conducted in a Japanese language class for international students in Japan, and the goal of this class was to learn about different cultures based on the AUC-GS (Awareness, Understanding, Coping, General Culture, and Specific Culture) learning model. Specifically, 60 international students from 10 countries and 10 Japanese students who participated as guests were divided into 10 groups and role-played scenes from an "end-of-year party with classmates and the professor." The Japanese students acted freely, showing international students natural interactions. The international students then repeated the role-plays with advice and feedback from the Japanese students. I analyzed the reactions of the learners before and after the role-plays using a questionnaire survey. Through role-playing, they learned about Japanese hierarchies, rituals associated with drinking, and practical Japanese phrases. Furthermore, their comments and the difference in their scores before and after the role-plays showed that their willingness to interact with Japanese people and their confidence in using the Japanese language increased. In addition, they recognized that facial expressions and attitudes are more important than speaking perfect Japanese. The international students learned about the various values and behaviors by engaging in role-plays and discussion with the Japanese students.
\end{abstract}

Keywords: International students in Japan, cross-cultural education, cross-cultural social skills, role-playing.

\section{Introduction}

In recent years, the number of international students has increased, and this trend has attracted considerable attention. However, with this increase, it is difficult to deal with their problems individually, and a wide viewpoint in educational practices is needed. It has been observed that education for international students is inadequate, and many studies have been conducted recently on the problems encountered by international students in foreign countries. International students living in Japan experience many cultural differences and are confronted with difficulties adapting to a different culture. Of these, cultural differences related to behavior in social situations and cultural differences in the expressions used in communication are known to be especially problematic (Takeuchi, Imahori, \& Matsumoto, 2001). Gong (2003) argued that a learning process such as acquiring new skills and understanding cultural standards and proper behavior are essential for cross-cultural adaptation. A number of methods have been developed and some include role-plays to improve students' awareness of their own and different cultures (Ishi, 1997). These methods are called "social skills learning." For skills learning, there are some educational practices in role-play such as "asking directions," "visiting professor," "using indirect expressions" and so on in Japan (for example, Tanaka \& Nakashima, 2006). These studies show that learners can effectively learn the values and behavior of Japanese culture.

In this research, I carried out a social skills learning session using role-play focusing on "how to behave in social gatherings" aimed at international students and investigated its effectiveness. 


\section{Methods}

\subsection{Participants}

Sixty international students from 10 countries (China, Korea, Thailand, Indonesia, Ukraine, Malaysia, Australia, France, Germany, Hungary) took part, 12 male and 48 female. Their Japanese proficiency level was upper intermediate. Their average age was 21.5 and each student had been in Japan either 4 months (46) or 10 months (14).

\subsection{Procedure}

Each participant completed a 90-minute session with role-plays. The sessions were conducted in a Japanese language class for international students in Japan, and the goal of this class was to learn about different cultures, including Japanese culture, based on the AUC-GS (Awareness, Understanding, Coping, General culture and Specific culture) learning model. This session aimed to teach the coping skills for a specific culture, in this case Japanese culture. Ten Japanese students participated as guests. International students and Japanese students were divided into 10 groups and role-played scenes from an "end-of-the-year-party with classmates and the professor." The international students spontaneously played acted the roles of teacher, senior, junior, and restaurant waiter while the Japanese students observed their actions.

The sessions consisted of the following eight parts: (1) explaining the subjects of scenes for role-plays; (2) role-plays by the international students; (3) getting advice and feedback from Japanese students; (4) model play by Japanese students; (5) explaining Japanese behavior; (6) international students repeated the role-plays with advice and feedback from the Japanese students; and (8) summary. In the session, participants evaluated their own performances. The overall contents of sessions consisted of the following three parts: (1) pre-session ratings (5-point scale); (2) a skill-learning role-play session; and (3) post-session ratings (5-point scale) and writing comments.

\section{Results and discussion}

Before and after each skill-learning session, I asked the participants to rate their learning. Shown below (Table 1) is the result of the T-test: all items: $\mathrm{Q} 1(\mathrm{t}(59)=11.19, \mathrm{p}<.01), \mathrm{Q} 2(\mathrm{t}(59)=3.03, \mathrm{p}<.01)$, $\mathrm{Q} 3(\mathrm{t}(59)=6.67, \mathrm{p}<.00), \mathrm{Q} 4(\mathrm{t}(59)=8.23, \mathrm{p}<.01)$ and $\mathrm{Q} 5(\mathrm{t}(59)=6.62, \mathrm{p}<.01)$ showed a significant increase in the after session. The results show that learners have learned in a practical way how to behave in social situations in Japan and have increased confidence regarding their behavior.

Some learner comments after the session were: "In Japan, I did not know that there was a specific seat in a social context where I was supposed to sit according to my age or position"; "Japanese students' behavior was completely different from ours"; "even if I cannot speak perfect Japanese, I think that I can have a good relationship with Japanese people if I can behave properly and politely"; "I became more confident, because I got comments from the Japanese students"; and "Actually, I would like to go to a year-end party with my lab mates due to this session." They recognized that facial expressions and attitudes are more important than speaking in perfect Japanese.

The learners acted freely in the first performance, then observed how the Japanese students behaved, and shared their awareness with all their class mates. In the second performance, they mimicked the Japanese performance and received comments from the Japanese students. In the final summary of the session, we deliberately avoiding creating stereotypes or promoting assimilation into Japanese culture. Specifically, I said that the behavior of the Japanese students in this role-play cannot be determined as the only correct behavior, nor is it intended to compel such behavior in the future. The comments from the learners also included comments that "my range of expressions and behavior was expanded" and "I can combine what I learned with my cultural experience, and use what I learned today." There were some comments along the lines of "I knew that Japanese people had specific cultural practices concerning the required manners in a hierarchical relationship, but I was surprised that the Japanese students who joined today's session behave this way in contexts such as their club activities. But it was good to learn skills that are actually useful in everyday life in Japan." These comments suggested that the participation of Japanese students prompted the learners' awareness, understanding, and learning. The international students learned about the various values and behaviors by engaging in role-plays and discussion with the Japanese students. 
Table 1. T-test statistics.

\begin{tabular}{lccccc}
\hline & $\begin{array}{c}\text { Pre } \\
M\end{array}$ & $\begin{array}{c}\text { Post } \\
M\end{array}$ & & & \\
Questions & $\begin{array}{c}M \\
(S D)\end{array}$ & $\begin{array}{c}\text { (SD) } \\
\text { t-value }\end{array}$ & $d f$ & Sig. \\
\hline $\begin{array}{l}\text { (1) I understand realistic Japanese cultural behavior in } \\
\text { formal situations. }\end{array}$ & $\begin{array}{c}2.57 \\
(0.93)\end{array}$ & $\begin{array}{c}4.08 \\
(0.70)\end{array}$ & 11.19 & 59 & $0.000^{* *}$ \\
\hline $\begin{array}{l}\text { (2) I understand how to deal with superiors like } \\
\text { professors and seniors, and can behave appropriately. }\end{array}$ & $\begin{array}{c}2.62 \\
(1.26)\end{array}$ & $\begin{array}{c}3.42 \\
(1.27)\end{array}$ & 3.03 & 59 & $0.004^{* *}$ \\
\hline $\begin{array}{l}2.77 \\
\text { (3) I have mastered ways to cope with features of }\end{array}$ & $\begin{array}{c}3.93 \\
\text { Japanese culture. }\end{array}$ & $\begin{array}{c}(1.11) \\
(0.84)\end{array}$ & 6.67 & 59 & $0.000^{* *}$ \\
\hline $\begin{array}{l}\text { (4) I can understand the Japanese cultural way of } \\
\text { thinking properly and can cope without } \\
\text { confusion. }\end{array}$ & $\begin{array}{c}4.03 \\
(1.06)\end{array}$ & $8.71)$ & 59 & $0.000^{* *}$ \\
\hline $\begin{array}{l}\text { (5) I have enough self-confidence to communicate } \\
\text { with Japanese people. }\end{array}$ & $\begin{array}{c}2.57 \\
(1.24)\end{array}$ & $\begin{array}{c}3.87 \\
(0.83)\end{array}$ & 6.62 & 59 & $0.000^{* *}$ \\
\hline
\end{tabular}

Note: *p<.05, **p<.01

\section{Further research}

In this study, I conducted a session using role-play for foreign students in Japan to learn about cultural behavior in social situations in Japan. Learners learned Japanese social behavior and way of thinking in practice through role-play. Future research is required to examine the effects of this session, including a follow-up investigation into whether the skills and knowledge that they learned in the role-play will be useful in actual daily life. In addition, I need to prepare various types of task scenes for role-plays.

\section{References}

Gong, Y. (2003). Goal orientations and cross-cultural adjustment: An exploratory study. International Journal of Intercultural Relations, 27, 297-305.

Ishi, S., Kume, A., Toyama, J., Hirai, K., Matsumoto, S., \& Midooka, K. (Eds). (1997). Cross-cultural communication handbook-From basic knowledge to application and practice. Tokyo: Yuhikaku Publisher. (in Japanese)

Takeuchi, S., Imahori, T. T., \& Matsumoto, D. (2001). Adjustment of criticism styles in Japanese returnees to Japan. International Journal of Intercultural Relations, 25, 315-327.

Tanaka, T., \& Nakashima, M. (2006). Trial of cross-cultural education with social skill learning. Cross-Cultural Education, 24, 28-37. (in Japanese) 